Check for updates

The BMJ

Cite this as: BMJ 2021;372:n192 http://dx.doi.org/10.1136/bmj.n192 Published: 21 January 2021

\section{Covid-19: Working in medicine is "pretty awful" right now, says college president}

\section{Abi Rimmer}

The second wave of covid-19 has put doctors under huge pressure, the Royal College of Physicians has warned, as two thirds of physicians report feeling tired or exhausted.

A survey of 25500 members of the college from across the UK, conducted on 2 November, received 1890 responses. It found that two thirds $(64 \%, 931)$ felt tired or exhausted, 48\% (687) felt worried, and just under a third (29\%, 424) felt demoralised. Almost a fifth $(19 \%, 280)$ said they have sought informal mental health support, such as speaking to colleagues or friends, during the pandemic. Just 10\% (155) said they had sought formal mental health support from either their employer, GP, or external services.

College president Andrew Goddard said he was concerned about the mental health of doctors, "There is no way to dress it up-it is pretty awful at the moment in the world of medicine. Hospital admissions are at the highest ever level, staff are exhausted, and although there is light at the end of the tunnel, it seems a long way away."

He said that before the pandemic, few physicians would have expected to need formal mental health support during their career.

After the pandemic, staff will be in desperate need of a break, Goddard said, and will need specific time away if they're to be at their best. "Doctors have demonstrated remarkable resilience throughout the pandemic, working under the most challenging conditions the NHS has ever faced, but they can't continue working this way forever," he said.

The college said that improvements in treatments for covid-19 meant that a much smaller proportion of hospitalised patients now required ventilation in intensive treatment units. This was, however, now placing huge pressure on the wider medical team in all specialties, particularly respiratory medicine.

In some hospitals, up to $95 \%$ of patients with covid-19 are receiving care on medical wards, the college said, and of the $20 \%$ of physicians who had been redeployed during this wave, most had gone to these wards.

Although the pandemic brings unprecedented pressure, the college said it considered understaffing to be the root of many problems, with $55 \%$ of consultant posts unfilled even before the pandemic. It has repeatedly called for medical school places to be doubled ${ }^{1}$ in order to grow the workforce and this month published a costed blueprint for making this happen. ${ }^{2}$

"Workforce shortages need to be urgently tackled post-pandemic if we're ever to reduce the immense pressure on NHS staff and ensure that they are prepared and supported to get the service back on an even keel," Goddard said,

Commenting on the survey findings, Saffron Cordery, deputy chief executive of NHS Providers, said the NHS workforce had come under relentless physical, psychological, and emotional pressure during the pandemic. "Trusts are committed to supporting the health and wellbeing of their dedicated staff," she said.

Rebecca Smith, managing director of NHS Employers, said the dedication and commitment of all NHS staff to keep going during the pandemic should not be understated. She recognised, however, that this way of working is unsustainable. "An honest conversation will be needed about how quickly the NHS can spring back once this peak subsides," she said. "We will continue to support employers across the health service with a range of resources to encourage their staff to seek help if they need it and would encourage more to do so."

Rimmer A. UK medical school places must double, says Royal College of Physicians. BMJ2018;361:k2781. doi: 10.1136/bmj.k2781 pmid: 29941479

2 Nabavi N. Apprenticeship model would better prepare medical students for practice, says RCP. BMJ 2021;372:n65. doi: 10.1136/bmj.n65 pmid: 33419723 